\title{
A comparative evaluation of clinical outcome of trans-abdominal hysterectomy, total laparoscopic hysterectomy and vaginal hysterectomy in non-descent cases
}

\author{
Krishnavtar Khandelwal, Shashi Lata Kabra, Syed Nawaz Ahmad*, Soma Mitra
}

Department of Obstetrics and Gynaecology, Deen Dayal Upadhyay Hospital, New Delhi, India

Received: 20 May 2016

Accepted: 10 June 2016

\section{* Correspondence:}

Dr. Syed Nawaz Ahmad,

E-mail: dr.syednawaz@gmail.com

Copyright: () the author(s), publisher and licensee Medip Academy. This is an open-access article distributed under the terms of the Creative Commons Attribution Non-Commercial License, which permits unrestricted non-commercial use, distribution, and reproduction in any medium, provided the original work is properly cited.

\begin{abstract}
Background: Hysterectomy is the most common operation performed by the gynaecologists and second most common surgery done after caesarean section all over the world. The objective of this study was to compare the clinical outcome in cases of trans-abdominal hysterectomy (TAH), non-descent vaginal hysterectomy (NDVH) and total laparoscopic hysterectomy (TLH).

Methods: It was a prospective comparative study conducted from November 2013 to June 2015 at Deen Dayal Upadhyay hospital in the department of obstetrics and gynaecology after approval by the ethical committee of the hospital. Intra-operative and post-operative clinical outcome of abdominal, laparoscopic and non-descent vaginal hysterectomies were compared during the study period. The patients were followed for a period of six months after surgery.

Results: During the study period we selected total 90 patients as per our inclusion criteria. Among 90 patients, 30 patients underwent total abdominal hysterectomy, 30 total laparoscopic hysterectomy and 30 non-descent vaginal hysterectomy. Patients were allocated to one of the surgical procedures by closed-envelope method. Commonest indication for hysterectomy in our study was dysfunctional uterine bleeding (52.2\%). Mean operating time in the TAH, TLH and NDVH group was $126.5 \pm 49.8$ minutes, $142.3 \pm 33.7$ minutes and $97.3 \pm 23.73$ minutes respectively. Mean blood loss in the TAH, TLH and NDVH groups was $319 \pm 82.6 \mathrm{ml}, 142.2 \pm 72.9 \mathrm{ml}$ and $201.7 \pm 49.3 \mathrm{ml}$ respectively. Intra-operative complications including haemorrhage, bladder and ureteric injury were maximum in the TAH group (6 patients) and minimum in the NDVH group ( 2 patients only). Post-operative complications including anaemia, febrile morbidity, wound infection and need for blood transfusion was maximum in the TAH group and minimum in the NDVH group.

Conclusions: From the above results it can be concluded that NDVH should be the procedure of choice unless contraindicated because of it being least time consuming and associated with least intra-operative and post-operative complication rate in addition to being cost-effective and cosmetically appealing.
\end{abstract}

Keywords: TAH, NDVH, TLH, Haemorrhage

\section{INTRODUCTION}

Hysterectomy is the most common operation performed by the gynaecologists and second most common surgery done after caesarean section all over the world. ${ }^{1}$ In U.S.A annual incidence of hysterectomy is 5, 90,000 (0.22\%), while in India incidence is $3,10,263 .^{2,3}$ Hysterectomy is commonly indicated for uterine leiomyomata, dysfunctional uterine bleeding, adenomyosis, endometriosis, utero-vaginal prolapse, premalignant and malignant conditions. ${ }^{4}$

Hysterectomy can be done either by abdominal route, vaginal or by laparoscopic approach. Abdominal 
hysterectomy is most commonly performed but laparoscopic hysterectomy is gaining popularity these days because of cosmesis, shorter hospital stay, faster recovery and low rate of infection but nevertheless it comes with some disadvantages like, higher cost, longer duration of surgery, and need for general anaesthesia. On the other hand vaginal hysterectomy $(\mathrm{VH})$ being devoid of the above disadvantages and mostly done under regional anaesthesia is preferred in high risk cases like obesity, heart diseases etc. and simultaneously is cosmetically appealing. Vaginal hysterectomy was traditionally used for utero-vaginal prolapse; however recent studies have proven efficacy and safety of $\mathrm{VH}$ in traditional contraindications like previous pelvic surgery, history of pelvic inflammatory disease, moderate to severe endometriosis, adnexectomy, nulliparity, and nondescended uterus, large uterus with or without fibroid. In our study we have compared clinical outcome of TAH, TLH and NDVH in terms of duration of surgery, blood loss, intra-operative and post-operative complications, requirement of blood transfusion and duration of hospital stay.

\section{METHODS}

The study was conducted in Deen Dayal Upadhyay Hospital from 1 November 2013 to 1 June 2015 after approval of the ethical committee. Patients in the age group of 30-60 years with symptomatic benign uterine pathology excluding utero-cervical descent but with good uterine mobility and uterine size less than 14 weeks were included in the study. Patients with severe cardiopulmonary conditions and previous abdominal or pelvic surgical procedures were not included in the study. Ninety patients fulfilling the inclusion criteria were enrolled in the study and were distributed equally; 30 each in TAH, NDVH and TLH group by closed-envelope method of randomization. Patients were followed for six month after surgery.

Operating time in TLH and TAH was calculated from the beginning of skin incision till the closure of the same incision at the end of the procedure. In NDVH operating time was calculated from incision on the cervico-vaginal junction to the placement of vaginal pack at the end of hysterectomy.

Amount of blood loss during laparoscopic hysterectomy was calculated as the difference between the total volume of liquid in the suction apparatus at the end of surgery and the volume of fluid used for irrigation. Blood loss during TAH and NDVH was estimated by calculating the blood volume in the suction machine, weighing soaked swabs and calibrated mops used during surgery. Length of hospital stay was defined as the number of days patient stayed in hospital after surgery excluding the day of surgery. Complications within first week after surgery were defined as early post-operative complications and after one week they were labeled as late post-operative complications.

\section{RESULTS}

Mean operating time in the TAH group was $126.5 \pm 49.8$ minutes, in the NDVH group it was $97.3 \pm 23.73$ minutes while in the TLH group it was $142.3 \pm 33.7$ minutes. Difference in the mean operating time was found to be statistically significant ( $\mathrm{p}<0.01$ and $F$ value 11.21 ). This shows that NDVH took minimum operating time. In multiple comparison after applying ANOVA with BONFERRONI followed by post hoc test, mean operating time was found statistically significant between the TAH and NDVH group and between the NDVH and TLH group, but not between the TAH and TLH group (Tables 1, 2 and 3).

Table 1: Operating time in three surgical procedures.

\begin{tabular}{|c|c|c|c|c|c|c|c|c|c|}
\hline \multirow{3}{*}{$\begin{array}{l}\text { Type of } \\
\text { surgery }\end{array}$} & \multirow{3}{*}{$\begin{array}{l}\text { Number of } \\
\text { subjects } \\
\mathrm{N}\end{array}$} & \multicolumn{8}{|c|}{ Time of operation (minutes) } \\
\hline & & \multicolumn{2}{|c|}{$50-100$} & \multicolumn{2}{|c|}{$110-150$} & \multicolumn{2}{|c|}{$160-200$} & \multicolumn{2}{|c|}{$210-250$} \\
\hline & & $\mathrm{n}$ & $\%$ & $\mathrm{n}$ & $\%$ & $\mathrm{n}$ & $\%$ & $\mathrm{n}$ & $\%$ \\
\hline TAH & 30 & 15 & 50.0 & 09 & 30.0 & 04 & 13.3 & 02 & 6.7 \\
\hline TLH & 30 & 03 & 10.0 & 19 & 63.3 & 06 & 20.0 & 02 & 6.7 \\
\hline NDVH & 30 & 20 & 66.7 & 10 & 33.3 & 0 & 0.0 & 0 & 0.0 \\
\hline Total & 90 & 38 & 42.2 & 38 & 42.2 & 10 & 11.1 & 04 & 4.5 \\
\hline
\end{tabular}

Mean blood loss in the TAH group was $319 \pm 82.6 \mathrm{ml}$, in the NDVH group it was $201.7 \pm 49.3 \mathrm{ml}$, while in the TLH group it was $142.2 \pm 72.9 \mathrm{ml}$, indicating that blood loss was minimal in the TLH group. Mean difference in the blood loss was found statistically significant $(p<0.01)$ between all the three groups. In multiple comparisons of mean blood loss after applying ANOVA and BONFERRONI followed by post hoc test, mean blood loss was found statistically significant between all the three groups of hysterectomy (Table 4 and 5). 
Table 2: Mean operating time and tests of significance.

\begin{tabular}{|llll|}
\hline \multirow{2}{*}{ Type of surgery } & $\mathbf{N}$ & \multicolumn{2}{c|}{ Operation time } \\
\hline TAH & 30 & Mean & SD \\
\hline TLH & 30 & 126.5 & 49.8 \\
\hline NDVH & 30 & 97.3 & 33.7 \\
\hline Total & $\mathbf{9 0}$ & $\mathbf{1 2 2 . 0 6}$ & $\mathbf{4 1 . 4}$ \\
\hline
\end{tabular}

Test of significance ANOVA $\mathrm{F}=11.21, \mathrm{p}<0.01$.
During surgery 5 patients $(16.7 \%)$ in the TAH group while only $2(6.7 \%)$ patients in the NDVH had haemorrhage. One patient in each TAH and TLH was complicated with bladder injury.

One patient in the TLH cohort was complicated by ureteric injury which was diagnosed in the post-operative period and patient was shifted to urology for further management. This finding suggested that the TAH was associated with maximum intra-operative complications while the NDVH had minimum complication (Table 6).

Table 3: Comparison of operating time.

\begin{tabular}{|c|c|c|c|c|c|c|}
\hline \multirow{2}{*}{ (I) Type of surger. } & \multirow{2}{*}{ (J) Type of surgery } & \multirow{2}{*}{$\begin{array}{l}\text { Mean } \\
\text { difference (I-J) }\end{array}$} & \multirow{2}{*}{$\begin{array}{l}\text { Standard } \\
\text { error }\end{array}$} & \multirow{2}{*}{ Significance } & \multicolumn{2}{|c|}{ 95\% Confidence interval } \\
\hline & & & & & Lower bound & Upper bound \\
\hline \multirow{2}{*}{ ТАН } & NDVH & $29.167^{*}$ & 9.640 & 0.010 & 5.63 & 52.70 \\
\hline & TLH & -15.833 & 9.640 & 0.312 & -39.37 & 7.70 \\
\hline \multirow[b]{2}{*}{ TLH } & TAH & 15.833 & 9.640 & 0.312 & -7.70 & 39.37 \\
\hline & NDVH & $45.000^{*}$ & 9.640 & 0.000 & 21.47 & 68.53 \\
\hline \multirow[b]{2}{*}{ NDVH } & TAH & $-29.167^{*}$ & 9.640 & 0.010 & -52.70 & -5.63 \\
\hline & TLH & $-45.000^{*}$ & 9.640 & 0.000 & -68.53 & -21.47 \\
\hline
\end{tabular}

*The mean difference is significant at the 0.05 level.

Minor post-operative complications like mild anaemia, fever and urinary tract infection were observed in $30 \%$ patients in the TAH group and $10 \%$ patients in the NDVH group. In our study major post-operative complications occurred in 8 patients $(8.8 \%)$, which included 3 cases $(3.3 \%)$ of wound gap, 1 case $(1.11 \%)$ of burst abdomen (diagnosed at $5^{\text {th }}$ post-operative day) and 1 case $(1.11 \%)$ of incisional hernia (diagnosed at 6 month's follow up visit) in TAH group, 2 cases of secondary haemorrhage $(2.20 \%)$ in the TLH group, and 1 case $(1.11 \%)$ of subcutaneous emphysema in the TLH group. The major post-operative complication rate was highest in the TAH group (5 cases). None of the patients in the NDVH group got any major complication post- operatively. However major complication rate in the entire study sample was statistically insignificant (p>0.05) (Table 7).

Table 4: Mean blood loss with the type of surgical procedure.

\begin{tabular}{|llll|}
\hline \multirow{2}{*}{ Type of surgery } & N & \multicolumn{2}{l|}{ Mean blood loss } \\
\hline TAH & 30 & 319 & 82.6 \\
\hline TLH & 30 & 142.2 & 72.9 \\
\hline NDVH & 30 & 201.7 & 49.3 \\
\hline Total & $\mathbf{9 0}$ & $\mathbf{2 2 0 . 7}$ & $\mathbf{1 0 1 . 1}$ \\
\hline
\end{tabular}

Test of significance ANOVA F $=50.035, \mathrm{p}<0.01$.

Table 5: Comparison of blood loss among three surgical procedures.

\begin{tabular}{|c|c|c|c|c|c|c|}
\hline \multirow{2}{*}{$\begin{array}{l}\text { (I) Type of } \\
\text { surgery }\end{array}$} & \multirow{2}{*}{$\begin{array}{l}\text { (J) Type of } \\
\text { surgery }\end{array}$} & \multirow{2}{*}{$\begin{array}{l}\text { Mean difference } \\
\text { (I-J) }\end{array}$} & \multirow{2}{*}{$\begin{array}{l}\text { Standard } \\
\text { error }\end{array}$} & \multirow{2}{*}{ Significance } & \multicolumn{2}{|c|}{$95 \%$ Confidence interval } \\
\hline & & & & & Lower bound & Upper bound \\
\hline \multirow{2}{*}{ TAH } & $\mathrm{NDVH}$ & $117.833^{*}$ & 18.000 & 0.000 & 73.89 & 161.77 \\
\hline & TLH & $176.833^{*}$ & 18.000 & 0.000 & 132.89 & 220.77 \\
\hline \multirow{2}{*}{ TLH } & TAH & $-176.833^{*}$ & 18.000 & 0.000 & -220.77 & -132.89 \\
\hline & NDVH & $-59.000^{*}$ & 18.000 & 0.005 & -102.94 & -15.06 \\
\hline \multirow{2}{*}{ NDVH } & TAH & $-117.833^{*}$ & 18.000 & 0.000 & -161.77 & -73.89 \\
\hline & TLH & $59.000^{*}$ & 18.000 & 0.005 & 15.06 & 102.94 \\
\hline
\end{tabular}

*The mean difference is significant at the 0.05 level. 
Table 6: Intra-operative complication rate with different surgical procedures.

\begin{tabular}{|lllllllll|}
\hline Type of complications & \multicolumn{1}{c}{ TAH $(\mathrm{N}=30)$} & \multicolumn{2}{c|}{ TLH $(\mathrm{N}=30)$} & \multicolumn{2}{c|}{ NDVH $(\mathrm{N}=30)$} & \multicolumn{3}{c|}{ Total (N=90) } \\
\hline & $\mathrm{n}$ & $\%$ & $\mathrm{n}$ & $\%$ & $\mathrm{n}$ & $\%$ & $\mathrm{n}$ & $\%$ \\
\hline Haemorrhage & 05 & 16.7 & 04 & 13.3 & 02 & 6.7 & 11 & 12.2 \\
\hline Bladder injury & 01 & 3.3 & 01 & 3.3 & 0 & 0.0 & 02 & 2.2 \\
\hline Ureter injury & 0 & 0.0 & 01 & 3.3 & 0 & 0.0 & 01 & 1.1 \\
\hline Total & $\mathbf{0 6}$ & $\mathbf{2 0 . 0}$ & $\mathbf{0 5}$ & $\mathbf{2 0 . 0}$ & $\mathbf{0 2}$ & $\mathbf{6 . 7}$ & $\mathbf{1 4}$ & $\mathbf{1 5 . 5}$ \\
\hline
\end{tabular}

*One women developed both haemorrhage and bladder injury.

Table 7: Post-operative complications and their association with different surgical procedures.

\begin{tabular}{|c|c|c|c|c|c|c|c|c|}
\hline \multirow{3}{*}{$\begin{array}{l}\text { Type of complications } \\
\text { Minor complications }\end{array}$} & \multicolumn{8}{|c|}{ Type of surgery } \\
\hline & \multicolumn{2}{|c|}{ TAH $(\mathrm{N}=30)$} & \multicolumn{2}{|c|}{ TLH $(\mathrm{N}=30)$} & \multicolumn{2}{|c|}{ NDVH $(\mathrm{N}=30)$} & \multicolumn{2}{|c|}{ Total $(\mathrm{N}=90)$} \\
\hline & $\mathrm{n}$ & $\%$ & $\mathrm{n}$ & $\%$ & $\mathrm{n}$ & $\%$ & $\mathrm{n}$ & $\%$ \\
\hline Anaemia & 06 & 20.0 & 02 & 6.6 & 01 & 3.3 & 09 & 10.0 \\
\hline Fever & 03 & 10.0 & 03 & 10.0 & 01 & 3.3 & 07 & 7.8 \\
\hline UTI & 0 & 0.0 & 02 & 6.6 & 01 & 3.3 & 03 & 3.3 \\
\hline Total & 09 & $\mathbf{3 0 . 0}$ & 07 & 23.2 & $\mathbf{0 3}$ & 10.0 & 19 & 21.1 \\
\hline Test of significance & \multicolumn{8}{|c|}{ Chi square value $=3.32, \mathrm{df}=2, \mathrm{p}>0.05$} \\
\hline \multicolumn{9}{|l|}{ Major complications } \\
\hline Wound gap & 03 & 10.0 & 0 & 0.0 & 0 & 0.0 & 03 & 3.3 \\
\hline Secondary haemorrhage & 0 & 0 & 02 & 6.6 & 0 & 0.0 & 02 & 2.2 \\
\hline Others & 02 & 6.6 & 01 & 3.3 & 0 & 0.0 & 03 & 3.3 \\
\hline Total & 05 & 16.6 & $\mathbf{0 3}$ & 10.0 & $\mathbf{0}$ & $\mathbf{0 . 0}$ & 08 & 8.8 \\
\hline Test of significance & \multicolumn{8}{|c|}{ Chi square value $=1.96, \mathrm{df}=2, \mathrm{p}>0.05$} \\
\hline
\end{tabular}

*Others include 1 case of each burst abdomen, incisional hernia and subcutaneous emphysema.

In our study blood transfusion was given to 6 patients $(20.00 \%)$ in the TAH group, followed by 5 patients $(16.67 \%)$ in the TLH group and only 3 patients $(10.00 \%)$ in the NDVH group. However this was found statistically insignificant $(\mathrm{p}>0.05)$ (Figure 1).

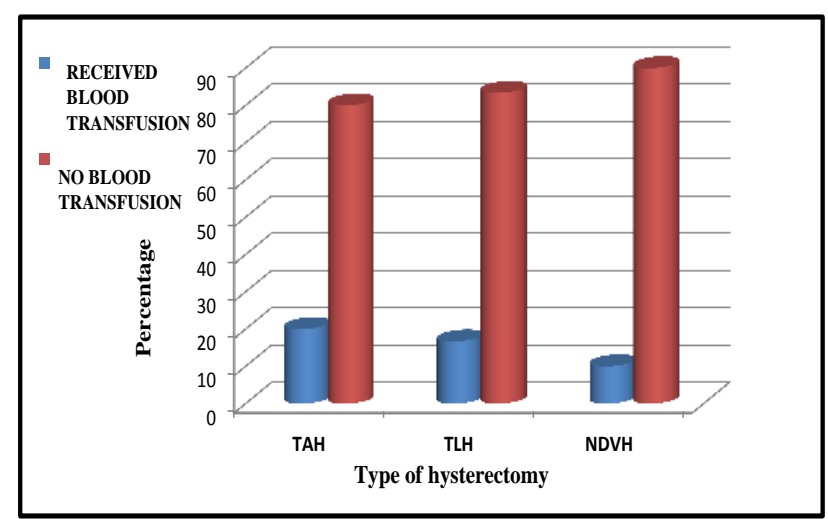

Figure 1: Comparison of the blood transfusions among the surgical procedures.

Mean duration of hospital stay in TAH was $5.03 \pm 3.77$ days in the NDVH group was $3.5 \pm 1.075$ days and in the TLH group it was $4.03 \pm 2.56$ days. On applying ANOVA it was found statistically insignificant $(p>0.05)$.
At 1 week of follow up, total 10 patients were found complicated; 6 patients $(20 \%)$ in the TAH group, 4 patients $(13.33 \%)$ in the TLH group but none in the NDVH group. It was found statistically significant $(\mathrm{p}<0.05)$ (Figure 2).

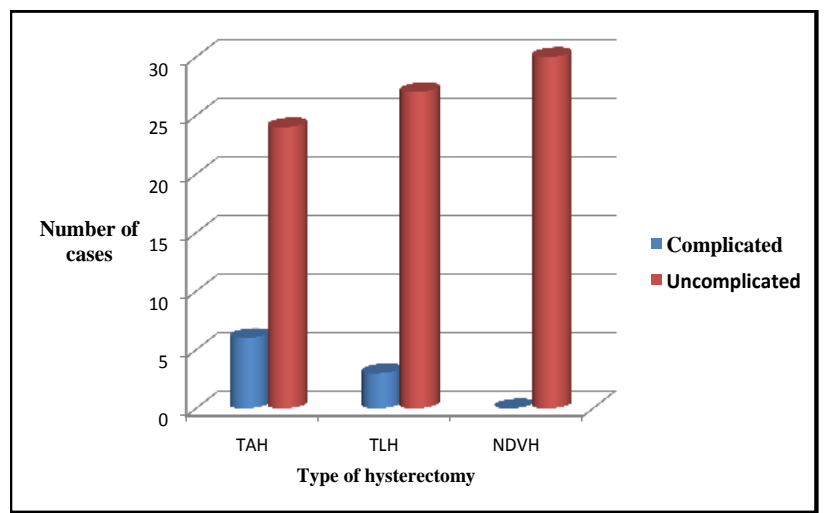

Figure 2: Cumulative complication rate associated with different surgical procedures.

Five patients, 3 in the NDVH group and 1 case each in TAH and TLH cohort didn't report at 6 month's follow up. 


\section{DISCUSSION}

Dysfunctional uterine bleeding was the commonest indication for the hysterectomy in our study [47 patients $(52.2 \%)$ ], followed by fibroid 27 patients $(30.00 \%)$, complex endometrial hyperplasia 10 patients $(11.1 \%)$ and the adenomyosis in 6 patients $(6.7 \%)$. In our study commonest indication $(40 \%)$ for hysterectomy in the NDVH group was dysfunctional uterine bleeding.

Similar indication for NDVH was reported by Mehla S et al $(45.7 \%)$ and Mehta ST et al (41\% cases). ${ }^{5,6}$ In the TLH group commonest indication was dysfunctional uterine bleeding [18 patients (60\%)] followed by fibroid $(30.00 \%)$, which was comparable to study by Patel et al. ${ }^{7}$

In the NDVH group, operating time in 20 patients $(66.7 \%)$ was between 50 to 100 minute and in the remaining 10 patients $(33.3 \%)$ it was 110 to 150 minute (mean $=97.3 \pm 23.73$ minutes) which was comparable to the studies by Mehla $\mathrm{S}$ et al (mean=90 minutes) and Shahana et al (mean=90 minutes in $66.66 \%$ cases)., Duration of surgery in the TAH group ranged between 70 minutes to 250 minutes (mean $=126.5 \pm 49.8$ minutes). In the studies by V. Mahasani et al (TAH 1 hour 20 minutes and NDVH 45 minutes) and Fatima et al (TAH=99.2 minutes and $\mathrm{VH}=79.6$ minutes) operating time was less for the vaginal route compared to the abdominal. ${ }^{9,10}$ Mean operating time in the TLH group was $142.3 \pm 33.7$ minutes. In the study by Patel et al in laparoscopic hysterectomy took almost double the time as NDVH (LH 2 to 4 hours; NDVH 1 to 2 hour). ${ }^{7}$ Mean duration of surgery of the TAH and TLH groups in our study was comparable to Sutasanasuang et al (TAH 91.1 \pm 53.6 minutes; TLH $218.4 \pm 79.3$ minutes). ${ }^{11}$ In the study by Dewan $\mathrm{R}$ et al the mean operating time for NDVH was only 54.5 minutes which is even less than our study. ${ }^{12}$ Similar were the conclusions of the comparative study between TAH and NDVH for non-prolapsed uterus by Singh et al. ${ }^{13}$ So it can be concluded that vaginal hysterectomy takes far less time compared to abdominal and laparoscopic procedures and hence complications due to prolonged surgery like deep vein thrombosis and postoperative infections and cost can be reduced in addition to being cosmetically better.

Mean blood loss in the NDVH group was $201.7 \pm 49.3 \mathrm{ml}$ which was comparable to studies by Mehla et al $(205 \mathrm{ml})$ and Shahana et al $(72.20 \%$ cases had blood loss up to 200 $\mathrm{ml}){ }^{5,8}$ In the study by Mahasani $\mathrm{V}$ et al NDVH had almost one forth the blood loss as TAH group (NDVH $60 \mathrm{ml}$ and TAH $250 \mathrm{ml}){ }^{9}$ Mean blood loss in the TLH group was $142.2 \pm 72.9 \mathrm{ml}$. Intra-operative complication occurred in 14 patients $(15.5 \%)$, with 6 patients in TAH group, followed by 5 patients in TLH group and 2 patients in the NDVH group. Our TAH study group was complicated by hemorrhage in 5 patients $(16.7 \%)$ and bladder injury in 1 patient $(3.3 \%)$. In the NDVH group hemorrhage was the only intra-operative complication and occurred in 2 patients $(6.7 \%)$. These results were comparable to the study by Mahasani $\mathrm{V}$ et al. ${ }^{9}$ In the study by Fatima et al bladder injury occur in 4 cases $(2.3 \%)$ of TAH and 1 case $(1.9 \%)$ of $\mathrm{VH}$, while ureteric injury occurred only in 1 case $(0.6 \%)$ of TAH but no case in $\mathrm{VH}^{10}$ In the TLH group of our study hemorrhage occurred in 4 patients (13.3\%), 1 patient $(3.3 \%)$ had bladder injury and 1 patient $(3.3 \%)$ had hemorrhage with ureteric injury, which was comparable to study by Patel R et al (bladder injury occurred 2 cases of TLH). ${ }^{7}$ In Sutasanasuang intra-operative complication rate in TAH was $16.67 \%$ which was found comparable to our study $(20 \%) .^{11}$

In our study 14 patients $(15.55 \%)$ required blood transfusion which comprised of 6 patients $(20.00 \%)$ in the TAH group, 5 patients $(16.67 \%)$ in the TLH group and only 3 patients $(10.00 \%)$ in the NDVH group. These results were comparable to the studies by Mehla $\mathrm{S}$ et al (4 cases in NDVH) and Mahasani $\mathrm{V}$ et al (blood was required in 6 cases of the TAH group and none in the NDVH group). 5,9

Most common post-operative complication in our study was anaemia which complicated 6 cases of TAH, 2cases of TLH and only one case of NDVH. Second most common post-operative complication was febrile illness which complicated 3 cases each in the TLH and TAH group but only one case of NDVH. In the study by Mittal $\mathrm{P}$ et al fever and infections were commoner in the abdominal hysterectomy group compared to the vaginal. ${ }^{14}$ In the systematic review by Johnson et al vaginal route was associated with fewer non-specific infections and febrile episodes compare to the laparoscopic and transabdominal route. ${ }^{15}$

Hospital stay in our study ranged between 3 days to 15 days. More than $2 / 3^{\text {rd }}$ of patients were discharged within 3 days. Only 7 cases $(7.8 \%)$ were hospitalized for more than 7 days because of associated intra-operative and post-operative complication. Sixty percent patients in the TAH group were discharged within 3 days. In the TLH group 22 patients $(73.3 \%)$ were discharged within 3 days. In the NDVH group 22 patients $(73.3 \%)$ were hospitalized for 3 days and 8 patients $(26.7 \%)$ were hospitalized for 4 to 7 days. In NDVH group no patient was hospitalized for more than 7 days, which was comparable to Mehla S et al (5 days), Dewan R et al (3 days). ${ }^{5,12}$ Mean duration of hospital stay in the TAH group was $5.03 \pm 3.77$ days, in the NDVH group $3.5 \pm 1.075$ days and in the TLH group it was $4.03 \pm 2.56$ days which was comparable to the studies by Sutasanasuang $\mathrm{S}$ et al (TAH $5.3 \pm 4.3$ days and TLH $3.2 \pm 1.1$ days) and Singh A et al, (NDVH 3.71days and TAH 7.84 days). ${ }^{11,13}$

At 6 month follow up there one case of incisional hernia was found in the TAH group but no complication in the TLH and NDVH group. However 5 patients were lost to follow up; 3 cases in the NDVH group and 1 case in TAH group and 1 case in the TLH group. 


\section{CONCLUSION}

From our study we reached to the conclusion that vaginal route for hysterectomy can be tried for most of the benign surgical conditions of the uterus. We recommend that NDVH should be the procedure of choice unless contraindicated because of it being least time consuming and associated with least intra-operative and post-operative complication rate in addition to being cost-effective and cosmetically appealing.

Funding: No funding sources Conflict of interest: None declared

Ethical approval: The study was approved by the Institutional Ethics Committee

\section{REFERENCES}

1. Te linde's. Operative gynecology $10^{\text {th }}$ editionAbdominal hysterectomy, Howard W. jones; 111.

2. Statistic of hysterectomy in world- The national women's health information centre (CDC). Available at URL: www. Mediciglobal.com.

3. Statistic of hysterectomy in India. Available at URL: www.mediciglobal.com.www.cure research.com.

4. Kovac SR, Cruikshank SH. Guidelines to determine the route of oophorectomy with hysterectomy. Am J Obstet Gynecol. 1996;175:1483-8.

5. Mehla S, Chutani N, Gupta M. Non decent vaginal hysterectomy: personal experience of 105 cases. Int $\mathbf{J}$ Reprod Contracept Obstet Gynecol. 2015;4(1):61-5.

6. Mehta ST, Trivedi YN, Bhalodia P. Role of nondescent vaginal hysterectomy in advancing gynecological practice. NHL Journal of Medical Sciences. 2014;3(1):55-8.
7. Patel R, Chakarvarty N. Comprative study of laparoscopic hysterectomy versus vaginal hysterectomy. Int $\mathbf{J}$ Med Sci Public Health. 2014;3(3):335-7.

8. Begum S, Akhtar R, Barua S, Ferdous J. A cross sectional descriptive study on non-descent vaginal hysterectomy (NDVH). Chattagram Maa-O-Shishu Hospital Medical College Journal. 2014;13(1):13.

9. Mahasani V, Suchdeva R, Aggarwal A. Hysterectomy-which approach? People's Journal of Scientific Research. 2014;7(1):17-21.

10. Shantini NF, Poolmar GK, Jayasree M, Bupathy A. Evaluation of complication of abdominal and vaginal hysterectomy. Int J Reprod Contracept Obstet Gynecol. 2012;1(1):7-11.

11. Sutasanasuang S. Laparoscopic hysterectomy versus total abdominal hysterectomy: a retrospective comparative study. J Med Assoc Thai. 2011;94(1):8-16.

12. Dewan R, Agarwal S, Minocha B, Sen SK. Nondescent vaginal hysterectomy: an experience. J Obstet Gynaecol India. 2004;54(4):376-8.

13. Singh A, Bansal S. Comparative study of morbidity and mortality associated with non-descent vaginal hysterectomy based on ultra-sonographic determination of uterine volume. Int Surg. 2008;93(2):88-94.

14. Mittal P, Andiliya A, Bansiwal R, Suri J, Singal S. Enlarged uterus through a natural orifice: worth an effort? A randomized controlled trial. Int J Reprod Contracept Obstet Gynecol. 2014;3(4):1076-81.

15. Johnson N, Barlow D, Lethaby A, Tavender E, Curr L, Garry R . Methods of hysterectomy: systematic review and meta-analysis of randomised controlled trials. BMJ. 2005;330(7506):1478.

Cite this article as: Khandelwal $\mathrm{K}$, Kabra SL, Ahmad SN, Mitra S. A comparative evaluation of clinical outcome of trans-abdominal hysterectomy, total laparoscopic hysterectomy and vaginal hysterectomy in non-descent cases. Int J Reprod Contracept Obstet Gynecol 2016;5:2346-51. 